\title{
Deliberation in representative institutions: an analytical framework for a systemic approach
}

2017 | Journal Article | Accepted Manuscript (Postprint)

available at https://doi.org/10.18452/23790

licensed under CC BY 4.0

Final version published as:

Andreas Schäfer: Deliberation in representative institutions: an analytical framework for a systemic approach. In: Australian Journal of Political Science 52(3), 2017, pages 419-435. DOI: $10.1080 / 10361146.2017 .1330397$

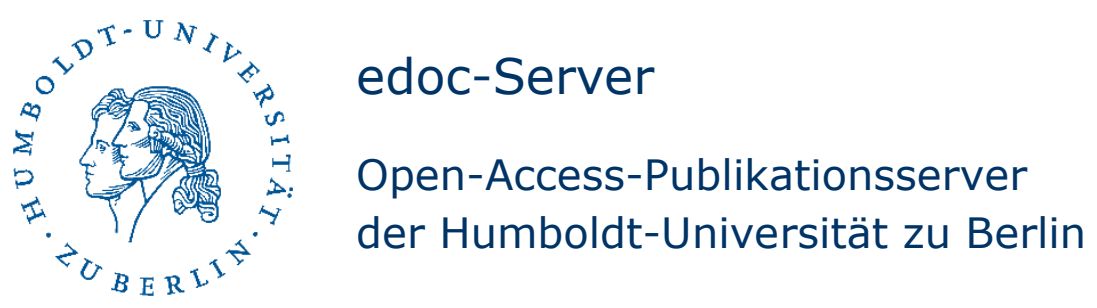




\title{
Deliberation in representative institutions: an analytical framework for a systemic approach
}

\author{
Andreas Schäfer \\ Institut für Sozialwissenschaften, Humboldt-Universität zu Berlin
}

\begin{abstract}
:
This article presents a novel analytical account of the relationship between deliberation and representation by reconstructing the specific institutional logics that guide deliberative action in parliaments. In contrast to the dominant generalised paradigm in empirical deliberation research it develops a contextualised-systemic approach. This article argues that the parliamentary context is characterised by a tension between two equally legitimate institutional logics: a discursive one, institutionalised through parliamentary procedures, and a positional one, constituted by relations of representation. The resulting theoretical model links the specific institutional and situational conditions to different forms and functions of deliberation. Depending on the specific balance between both logics deliberation fulfils functions of either integration or contestation. The model is applied to a comparative analysis of different cases of parliaments demonstrating how this account can advance both the comparative analysis of deliberation in representative institutions and the development of deliberative democracy after the systemic turn.
\end{abstract}

Keywords: deliberation, representation, systemic turn, parliament, institutional logics 


\section{Introduction}

The relationship between representation and deliberation is fraught with tension. On the one hand, there is no deliberation without representation. For deliberative encounters to be meaningfully interactive, they require some limitation of the number of actors involved, which makes deliberation 'inherently representative' (Bohman 2012, 76). On the other hand, if deliberation changes minds and positions as deliberative democratic theorists expect a potential problem arises: people who did not directly participate in the process do not have reasons stemming from deliberation itself to accept the outcome. This has been referred to as the 'scale problem' of deliberative democracy (Parkinson 2006, 5).

There are different approaches to tackle this complicated relationship. While research in comparative politics often neglects the deliberative dimension of electoral representative institutions (cf. Bächtiger 2014; Quirk and Bendix 2011), deliberative democratic theorists tend to shift their attention to non-electoral forms of representation (e.g. Dryzek and Niemeyer 2008; Kuyper 2016). Although the latter strand of research has produced important insights for the normative assessment of different forms of representation, we still lack a clear analytical understanding of how and under what conditions practices of deliberation and claims for representation facilitate or limit each other in different institutional contexts, be they formal/electoral or informal/non-electoral.

That is the point of departure for this article, which presents a novel, contextualised and systemic account for analysing the relationship between deliberation and representation in parliaments. The basic argument is that parliamentary deliberation takes place between the poles of two democratically legitimate institutional logics: a discursive one and a positional one. Relations of representation constitute a positional logic that fosters a commitment to positions developed before a deliberative encounter. By contrast, the discursive logic is institutionalised through procedures and norms of mutual justification that principally implies openness for changing positions. Different parliamentary arenas and conflict situations are characterised by a specific balance between both logics, which in turn determines the form deliberation takes, its dynamics, and the functions it fulfils.

Parliaments are particularly suited for studying this dynamic relationship. With their sophisticated coupling of representation, deliberation, and binding collective decision-making, parliaments play a unique role within democratic political systems. One might say that by 
combining different phases of deliberation in diverse arenas with varying degrees of publicity, parliaments build a deliberative system of their own. Given the systemic turn deliberative democratic theory has recently taken (Mansbridge et al. 2012), much can be learned from deliberation in parliamentary institutions. By focusing on the specific institutional logics in which parliamentary deliberation is embedded we gain fine-grained analytical tools that may help to understand the relationship between representation and deliberation in other contexts as well.

The article proceeds as follows: after critically reviewing the research on parliamentary deliberation in the next section, it argues that currently dominant generalised approaches to parliamentary deliberation should be complemented by a contextualised approach, which is detailed in three steps. The first is to build a context-sensitive concept of deliberation that enables us to identify the phenomenological and functional differentiation of deliberation in diverse settings. More specifically, the paper argues that an analytical definition should focus on the implicit rules that guide deliberation as a communicative practice and not on specific ethical motives of actors. The second step is to explain how the two institutional logics are constituted and why they stand in tension with each other. The third step is to introduce an analytic model that captures the conditions, processes, and functions of parliamentary deliberation. The model links the contextual institutional logics - mediated through the specific character of the respective political conflict - to the diverse practices of deliberation and to their potential functions. Typical deliberative functions range between the poles of integration and contestation.

This model will be applied to the comparative analysis of parliamentary deliberation with a focus on two levels. On the parliamentary level, I draw on insights from a case study on the German federal parliament. On the political system level, I compare the deliberative profiles of three cases (the German Bundestag, the US House of Representatives, and the European Parliament) that represent three distinct types of legislature. The article concludes with implications of the study for both empirical research on deliberation in representative settings and theoretical construction of a systemic model of deliberative democracy. 


\section{Empirical research on parliamentary deliberation: the generalised approach}

As Mansbridge et al. (2012) have argued, rather than looking at diverse sites of deliberation in isolation a systemic approach is needed that takes into account their interdependencies and respective functions for entire deliberative systems. Despite this plea, generalised approaches to the analysis of deliberation in parliaments are dominating the research agenda. As a result, the characteristic institutional embeddedness of parliamentary deliberation remains understudied on at least two levels: first, the specific role of deliberation within parliaments, and, second, the particular functions of parliaments in democratic systems as a whole. Consequently, empirical research has yet to fully account for this contextual specificity of parliamentary deliberation.

Parliamentary deliberation has not figured prominently in empirical deliberation research. ${ }^{1}$ Two pioneering studies that applied variants of Habermas' theory of deliberative politics to the analysis of parliaments arrived at sceptical conclusions. Based on a comparative analysis of discussions on the regulation of stem cell research in Germany, Landwehr and Holzinger (2010) concluded that a citizen's conference demonstrated high degrees of deliberation while the plenary debate in the German Federal Parliament lacked any deliberative quality: it was not discursive and had little impact on preference transformation.

While that study suggests an absence of deliberative quality in German parliamentary debates, a seminal study by Steiner et al. (2004) finds evidence of variation in the quality of parliamentary deliberation in different political systems. To arrive at this conclusion, Steiner et al. (2004) applied their Discourse Quality Index (DQI) ${ }^{2}$ to parliamentary deliberation in Switzerland, Germany, the United Kingdom and the United States. Although both studies provide new and valuable insights into the causal relationships between conditional factors, the quality of deliberation, and its effects, at least three interrelated critiques can be levelled. First, they do not take into account the functional differentiation of parliamentary deliberation: parliamentary decision-making proceeds through diverse arenas (party group meetings, factional and inter-factional circles, committee meetings, hearings, plenary debates) that all contribute to the overall result by fulfilling different functions. Second, both studies undervalue the critical dimension of deliberation (Dryzek 2000; White and Farr 2012): its potential to challenge dominant positions. Emphasising this critical potential could respond to theoretical critics like Mouffe (2005), Sanders (1997) and Young (2000) who argue that deliberation is too much oriented towards consensus and the status quo, but both of the 
parliamentary studies privilege consensual behaviour over contestation by focusing on either the degree of unification or coordinative adjustment of positions as the appropriate outcome of deliberation. Third, and related to the previous points, there is a need to focus on interaction rather than on individual speech acts in order to capture discourse as an interactional phenomenon - one that can only partially and indirectly be identified in individual communicative acts.

These strands of research, which I will refer to as the 'ethical-evaluative' paradigm, can be complemented with an alternative, contextualised-systemic approach to the analysis of parliamentary deliberation. The ethical-evaluative approach is characterised by the benchmarking application of a generalised measure to diverse contextual settings, by focusing on individual ethical behaviour, and by privileging the consensus building potential of deliberation. In contrast, the contextualised-systemic approach aims to account for the functional specificity of deliberation in diverse settings by incorporating existing deliberative practices and considering their diverse functions.

Limitations of the ethical-evaluative paradigm have been acknowledged. For instance, Bächtiger et al. (2010) identify 'blind spots' in approaches like the DQI. As a solution, they propose a sequential approach to evaluating deliberation that allows for the possibility that the different 'virtues' of deliberation can emerge in different phases of the deliberative process (Bächtiger et al. 2010). However, the sequential approach is basically just an extension of the DQI because it locates alternative forms of communication (e.g. storytelling) at lower points on the evaluative measurement scale. These alternative forms are understood as 'non-rational' complements to proper deliberation (Bächtiger et al. 2010, 54). Thus, a functional differentiation of deliberation as such is still not considered.

In another extension of the DQI, Lord and Tamvaki (2013) acknowledge that purely consensual behaviour is only partially appropriate for the parliamentary context. To fully assess the justificatory function of plenary debates, they add theoretical indicators that recognise that deliberation may legitimately adopt a controversial or adversarial character. Despite this, the study still suffers from some of the limitations of the ethical-evaluative paradigm. It focuses on individual conduct in plenary debates without sufficient reference to the interdependencies of deliberative acts within the parliamentary process and to the institutional specificities that might trigger peculiar dynamics of parliamentary deliberation. 
Thus, we need to go one step further in order to take into account the institutional specificity and functional embeddedness of parliaments.

\section{An analytical framework for a contextualised approach}

The underlying assumption of the contextualised-systemic approach is that deliberation is not only a theoretical concept, but also an observable political practice that takes on diverse forms in different contexts. Following this supposition, empirical research on deliberation needs to do two things. First, it needs to develop an analytical concept that captures the theoretical core of deliberation while remaining sensitive to diverse empirical manifestations of deliberative practice. Second, research on deliberation should reconstruct the specific institutional contexts in which the deliberative practices being investigated are embedded and which also provide the mechanisms that produce the specific dynamics of parliamentary deliberation. I address the first need in the following section and then turn to the second requirement.

\subsection{Towards an analytical concept of deliberation}

In the literature on deliberative democracy, the concept of deliberation is regularly connected to normative assumptions regarding the ethical orientation of deliberating actors (e.g. Chambers 2003, 309). I argue, however, that we should not include a specific ethical quality of actor's motivations into a conceptual definition of deliberation, ${ }^{3}$ because this produces blind spots in our analytical tools that hinder us from capturing important aspects of deliberative practice, such as more contentious forms of deliberation. Furthermore, focusing on individual motives tends to isolate speech acts from the context of deliberative interaction, which in turn is important to understand the potential communicative dynamic and resulting quality of deliberation. As I will show below, actor motivations will legitimately vary across contexts. In this way, they cause variations in deliberative practices that despite their diversity can comply with basic assumptions outlined in deliberative theory. Therefore, I suggest defining deliberation as a practice of communication not characterised by a distinct ethical orientation of actors but constituted by certain implicit rules that normatively constrain actors in their behaviour. 
Jon Elster's (1999) distinction between arguing and bargaining provides a good starting point for clarifying these rules of deliberative practices. Relating to this distinction, Habermas writes:

Arguing and bargaining are practices that force participants to comply with certain conditions of communication. Anyone who engages in discourse must operate with pieces of information and reasons that may convince an impartial third party, even if the speaker is thereby pursuing strategic ulterior motives. And anyone who seeks compromises [...] must have at his disposal means and incentives with which he can influence the other party by threatening or rewarding. (2007, 422; own translation, emphasis added)

Thus, the implicit conditions or rules of deliberation are to be seen, at least to some extent, as independent of individual motivations, and as coming into play as soon as someone engages in this specific mode of communication. The individual motive can be mutual understanding, but it can also be strategic considerations if the actors play by the rules of deliberation - i.e. according to its argumentative logic - which then allows us to identify the resulting communicative interactions as deliberative practices.

This conceptual distinction is especially relevant for parliamentary contexts. Communicative processes in parliaments are embedded in a strategic environment due to the competitive relation among the party groups. This is not to say that strategic embeddedness renders deliberation impossible a priori. One could argue that partisan competition importantly drives and dynamises deliberative justification by reciprocally challenging differing conceptions of the common good (White and Ypi 2011; cf. Urbinati 2000).

In any case, deliberation has to follow the logic of argumentation in order to avoid communication breakdowns, such as the withdrawal of communication partners. Hence, while deliberation can appear with different individual motives of actors, an alignment with the specific implicit rules of the game is required, whenever actors want to effectively participate in deliberative practices (Habermas 2005). These rules demand the give and take of reasons, and a speaker must accept that other speakers will provide counter-arguments against his or her validity claims.

Of course, this does not mean that engagement in deliberative interaction automatically triggers proper arguments for and against validity claims, and only that. Depending on their motives, actors will have incentives to pretend to argue and simultaneously try to circumvent the justification requirement by resorting to ad hominem arguments, by agenda shifting, by 
reframing, etc. However, the implicit rules of deliberative interaction provide the mechanism for critically scrutinising and contesting such moves by the other communication partners, judging them against the criteria of truth, rightness, and sincerity, for example (Habermas 1987, 376). Thus, engagement in deliberation does not so much force actors to be authentic and sincere in their arguments, but rather to accept that their statements and arguments be judged according to the norms of authenticity and sincerity. This increases the chance that the outcome of deliberation will be less influenced by manipulative aims than any individual speech act might be.

Having acknowledged that the same communicative logic can coincide with diverse motivations we can conclude that deliberation may appear in different phenomenological variants due to different motivations. Along these lines, we can distinguish different action orientations (cooperative, competitive, confrontational) that initiate diverse forms of arguing (Saretzki 2009, 163). Whereas cooperation is a motive that constitutes an orientation towards the integration of divergent points of view, confrontation motivates an orientation towards the contestation of competing positions.

Deliberation encompasses those modes of communication that use argumentation. Pure bargaining would generally be excluded from the conceptual definition of deliberation, but since we can interpret arguing and bargaining semantically as non-symmetrical and nonexclusive conceptual opposites, there are also hybrid forms of communication occupying a grey zone of overlapping membership along the continuum between both ideal-typical poles (see Goertz and Mahoney 2012, 162-167; cf. Warren and Mansbridge 2016).

In short, the first analytic step conceptualized deliberation as a communicative practice that is guided by the implicit rules of argumentative exchange. Within these constraints, deliberation can take diverse forms ranging from cooperative to rather confrontational modes. The form, dynamic and subsequent function of deliberation depends on action orientations that vary with contextual conditions. These contexts and their relationship to deliberative practices will be the object of the next analytic steps.

\subsection{The parliamentary context: Conflicting institutional logics}

According to the concept of deliberation outlined here, deliberation is a practice of communication that exerts causal influence by constraining and enabling the behaviour of 
those engaged in interactions. At the same time, however, the actual motives of actors as well as the forms, dynamics and functions of deliberation can vary across shifting contexts. If we exclude actor motives from the definition of deliberation, then we can treat them as part of the incentives and constraints that different contexts provide.

This requires that the institutional and situational context of communicative interaction be carefully assessed. In line with neo-institutionalist reasoning, institutions forge and stabilise a horizon of orientation for social action. The guiding assumption of the approach presented here is that the parliamentary context is characterised by a tension between two institutional logics ${ }^{4}$ : a discursive one and a positional one. These logics provide partly-conflicting guidelines for members of parliament.

For Habermas (1996, 307), parliaments are traditionally designed to follow a discursive logic. Decisions cannot be made immediately after a motion is brought into the legislative process, but only after a phase of deliberation in plenary and committee meetings. This is the case regardless of the possibility that clear majorities for and against a proposal exist from the outset. Procedures are structured to permit a plurality of voices from all perspectives and in a consecutive manner, which fosters alternating arguments for minority and majority positions. Finally, decisions have to be justified towards the public interest. In these ways, the process of decision-making is decelerated and left open to critical reflection. Moreover, members of parliament have, in principle, an independent mandate which means that they can change their positions as often and as drastically as they deem necessary. Although this freedom is seldom used due to party discipline, it provides parliamentarians with a formal autonomy that allows them to demand justifications for all decisions they do not immediately agree with.

However, a positional logic is institutionalised in parliaments as well, related to established political positions and based on relations of representation. According to Saward a relation of representation is constituted by the making of a representation claim and its acceptance by a respective audience (Saward 2010, 48). A claim for democratic representation to be acceptable requires that claimants align themselves with the norm of responsiveness (Pitkin 1967, 209) which is institutionalised through mechanisms of authorization and accountability (Urbinati and Warren 2008, 396). Thus, representatives are constrained in their political positioning by the expectations and judgements of those represented (cf. e.g. Plotke 1997, 28). ${ }^{5}$ 
In the parliamentary context, we find representative relations in two key respects. First, members of parliament represent their electoral constituencies. Second, they represent their party group within the parliament. For instance, within the bodies of the parliamentary process - plenum and committees - members tend to stand for the positions of their party group. The degree to which representatives are bound by the positions of their groups differs depending on group cohesion and discipline. While cohesion and discipline are generally expected to be strongest when there is a clear connection between the majority in parliament and the government, it might be lower in presidential systems where the government is not directly dependent on the stability of its party in parliament (Sieberer 2006, 152). The positional logic is further institutionalised in certain rights and privileges of party groups. And, as in other relations of representation, the logic is reinforced by normative expectations: representatives are judged by those they represent according to how well they pushed their original position.

The two logics stand in structural tension with each other. Deliberation demands that actors be willing to engage in the process of arguing and justification. This implies openness to changing one's stance in the face of convincing reasons. By contrast, relationships of representation demand that pre-established positions pass through the decision-making process with as little changes as possible. Here, the output is usually judged by those represented according to how well it meets their original expectation or at least how closely changes match their preferences.

This structural tension corresponds with the 'scale problem' of deliberative democracy (Parkinson 2006). According to the scale problem, deliberation requires representation, but if representatives leave their original positions there is no reason - stemming from deliberation itself - to acknowledge the change for those who have not participated in the process. I hypothesise that the positional logic is more pronounced in contexts with clear majorities and strong party groups that have a high degree of internal cohesion and discipline because, both majorities and oppositions will not feel the need to leave their position in order to win each other's support. Along similar lines, I hypothesise that the more intense and consequential intra-group deliberation is, the less intense and consequential inter-group deliberation will be because the effort put into the internal position building sets a strong incentive not to leave it (Schöne 2010, 373). 
It is important to note that this structural tension argument does not question the democratic legitimacy of either of the two logics. On the contrary, their legitimacy is buttressed by the specificities of parliamentary contexts. Whereas the discursive logic legitimises decisions arrived at through rational justification and argumentative engagement, the positional logic legitimises decisions based on public and partisan representation rooted in democratic elections and which, in turn, can be viewed as the result of deliberative processes about party programs and personnel in the public sphere (Habermas 2005, 390). Programmatic positions are to be understood as the articulation of the will of either a majority or minority of the people.

\subsection{A theoretical model of parliamentary deliberation}

I now synthesise the considerations regarding the concept und context of (parliamentary) deliberation in a theoretical model. As summarised in Figure 1, the model includes three dimensions: (a) the initial institutional and situational conditions, (b) the forms and practices of deliberation, and (c) their potential functions (see Figure 1).

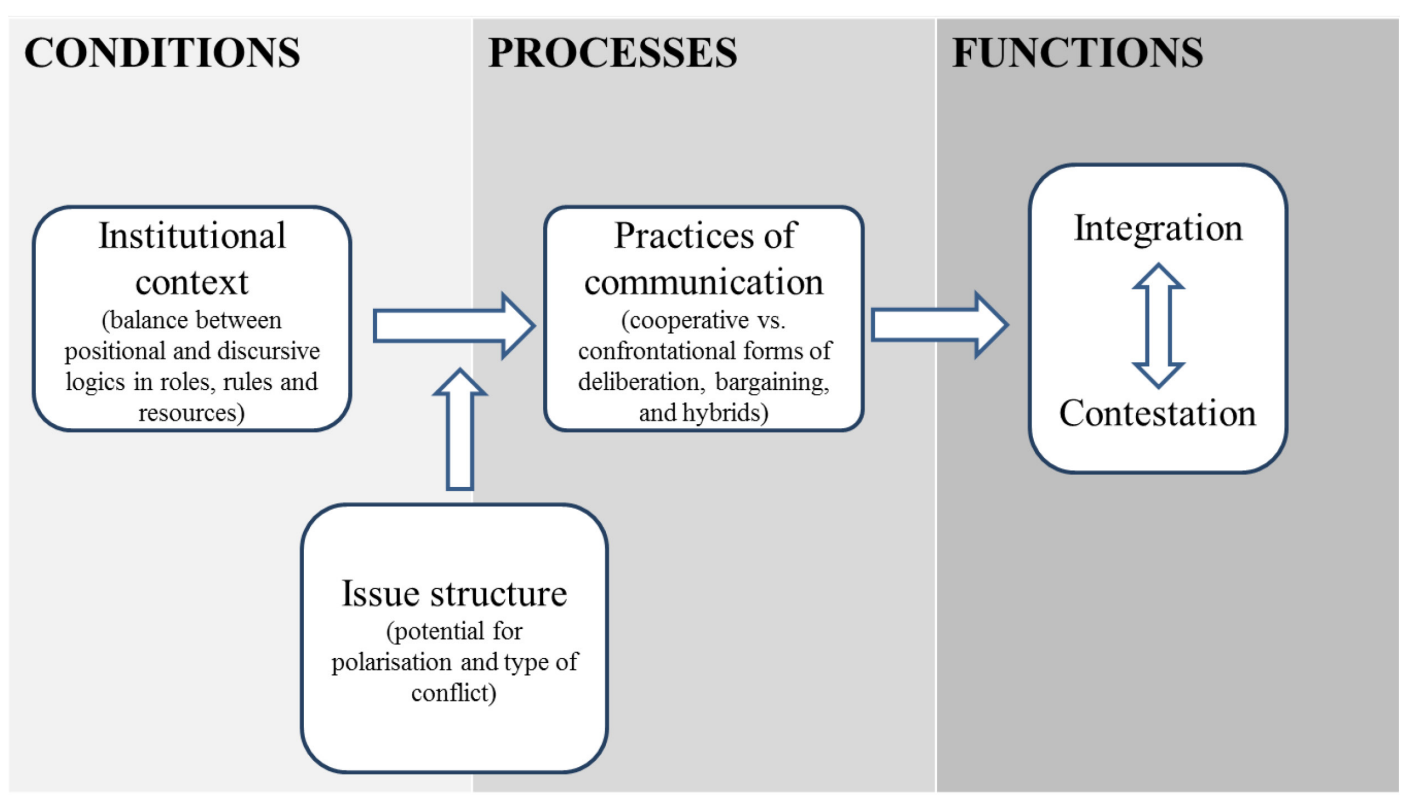

Figure 1. Theoretical model of parliamentary deliberation.

To outline the conditions of parliamentary deliberation, the model adopts a neo-institutionalist perspective for understanding institutional contexts (a). In this perspective, actors adopt formal and informal institutional conventions by conforming either to a 'logic of 
appropriateness' or a 'logic of consequentiality' (March and Olsen 1996). In the parliamentary context, institutional conditions are constituted by the tension between the aforementioned discursive and positional logics. Importantly, these logics are implemented in specific roles, rules, and resources. Whereas roles provide actor-specific and functional orientations, rules offer guidelines for situational contexts. Certain resources are also institutionalised or standardised to guide actors in their planning (e.g. time, expertise, and social relationships). Empirically, we should be able to identify the potentially conflicting orientations for social interaction that the discursive and positional logics create across roles, rules and resources. For example, as members of specific committees, parliamentarians often take on the roles of policy experts and of representatives of the respective party group at the same time. The former is likely to support a discursive logic, because it requires openness to technical or field-specific arguments. The latter is likely to stress a positional logic by staying in line with the position taken by the party group s/he represents.

Dovetailing with the institutional context is the situational context. This aspect of the conditions shaping parliamentary deliberation is characterised by the structure of the issue under consideration. In the literature on deliberation, two common dimensions undergird the issue structure: the type of conflict and the degree of polarisation. For the first dimension, a common typology is the distinction between conflicts over facts, over values, and of interests (Holzinger 2005): Value conflicts can be expected to enhance an inflexibility of positions, whereas conflicts over facts might be more accessible to discursive clarification and conflicts of interests prone to be tackled by bargaining. The second dimension of issue structure relates to the degree of polarisation (Steiner et al. 2004, 88-89). I will use the term polarisation potential in order to highlight the fact that polarisation is endogenous to the process. It can increase or decrease depending on other factors, such as the public salience of an issue. A higher polarisation potential will encourage the positional logic by widening the room for confrontation.

The model assumes that the issue structure interacts with the balance between the institutional logics by influencing the interpretation of the situation by the actors who then stress either the discursive or the positional roles, rules, and resources.

Turning to the process dimension of the model (b), parliamentary practices of communication are executed by the members of parliament based on their assessment of intersecting 
institutional and situational conditions. Practices mediate between institutions and concrete situations by providing a range of collectively recognised patterns of action that actors can use to address current challenges (Rüb 2009). Parliamentary practices can encompass different forms of deliberation as well as other forms of communication. Notably, deliberation may include forms of arguing and hybrids between arguing and bargaining, while other forms of communication will include pure forms of bargaining. Thus, forms and practices of communication can stand closer to either the discursive or the positional logic of the institutional context.

As some degree of competition among parties exists in all parliaments, it is safe to assume that parliamentary actors strategically evaluate the institutional and situational context before engaging in communicative exchanges. However, in such highly institutionalised realms, the choice of practices is restricted to the available, legitimate forms of communication. In short, even if parliamentary actors think strategically, they are still bound to follow a 'logic of appropriateness'. In this case, communication will be based either on the discursive or positional logic or a combination of both.

In concrete situations, actors will make judgements about the balance between discursive and positional logics and the issue structure, and will develop expectations about other discussants. Based on such strategic assessments of the context, actors can adopt two idealtypical deliberative orientations: towards cooperation or towards contestation. While the cooperative approach will imply more conciliatory forms of deliberation, the contentious approach will result into more confrontational. The stronger the discursive logic, the more likely the cooperative orientation will emerge. The stronger the positional logic, the more likely the orientation towards contestation will emerge.

Turning to the third dimension (c) of the theoretical model, the functions of parliamentary deliberation can be located on a scale between integration and contestation. Whereas the former closes the deliberative process, the latter re-opens it. These functions are to be fulfilled within the parliamentary procedure and for the political system as a whole. The functional performance of parliaments hinges on two contextual variables that condition the mode of deliberation and its effects: (1) the issue structure and (2) the balance of the institutional logics. This leads to the following hypotheses. All other things being equal, issues with a high polarization potential and conflicts over values will foster confrontational modes of 
deliberation. Here, deliberation will fulfil contestation functions - if the process of communication does not break down. On the other extreme, issues with a low polarization potential in conflicts over facts will foster integrative modes of deliberation that are likely to fulfil integrative functions.

If we keep the issue structure constant and focus on the second contextual variable, the balance of institutional logics, the model offers another set of predictions. The more the discursive logic dominates the parliamentary setting, the greater the chances are that cooperative modes of deliberation will fulfil integrative functions. If the positional logic is dominating, deliberation is likely to break down or to be substituted by bargaining. Thus, I assume that deliberation can only be effective if the discursive logic has at least a minimal degree of influence. If the positional and discursive logics are in equal balance, confrontational modes of deliberation and the fulfilment of contestation functions are more likely.

\section{Comparing forms and functions of parliamentary deliberation}

The next step is to apply the analytic framework to an illustrative analysis of parliamentary deliberation. This demonstrates how the contextualised-systemic approach produces results and insights that differ from and add to those generated by the generalised ethical-evaluative paradigm. This section starts with a comparison of issue structures and arenas within one parliament belonging to the parliamentary system type, then turns to a comparison of deliberative functions of different types of parliaments for their respective political system.

\subsection{Comparing issue structures and parliamentary arenas}

The German Bundestag is a typical case of a parliamentary system in which there is a clearcut division and dualism between the governing majority and the opposition (Lijphart 1992). As hypothesised above, this fact is expected to accentuate the positional logic within the parliamentary setting. Nevertheless, the question remains how strongly the institutionalised discursive logic will guide the process.

Focusing first on variations in the issue structure, case study evidence ${ }^{6}$ shows that deliberative practices and dynamics clearly differ depending on the type of conflict and degree of 
polarization. Highly polarized and ideological topics narrow the space for an effective exchange of arguments by fostering the positional logic of the parliamentary process as expected. In the most extreme cases of ideological polarization members of parliament even report communicative breakdowns in committee sessions - as for example in 2010 during a conflict over the prolongation of the runtime of nuclear power plants, when substantial debates were substituted by second order disputes over the rules of procedure and by mutual accusations of eroding the parliamentary process (cf. Deutscher Bundestag 2010, 7159-7166).

However, even if conflicts are ideologically polarized, the discursive logic of procedural rules still pushes actors to engage in deliberative encounters in most instances. In addition, members of parliament report that committee deliberation is normally characterized by a high level of respect based on the mutual recognition of their roles as policy experts that strengthens the discursive logic of the setting. However, this does not mean that the positional logic will be completely overridden, at least not in the formal arenas of decision-making. In such, rather common cases, both logics are equally balanced. The result is the adoption of confrontational modes of deliberation by the actors that aim at mutual contestation more than consensual integration of positions, although arguments are still designed to convince opponents. By contrast, issues framed as conflicts over facts with less salience for partisan polarization regularly leave room for cooperative deliberation between members of different party groups. This cooperation is supported by a shared role as policy experts, by social resources of professional trust and informal relationships that can result in positional accommodation.

If we keep the second dimension, the issue structure, constant, we can trace variations in balancing institutional logics along the parliamentary decision-making process. Deliberation within the German Bundestag takes place in intra- as well as inter-party arenas (both formal and informal) that typically vary in their balancing of the discursive and positional logic. Backed up by a robust party discipline as well as by far-reaching rights of parliamentary party groups, the positional logic turns out to be strong in encounters between opposition and governing majority. On the one hand, this condition limits the possibility of reaching interparty consensual agreements through deliberation in parliament. As an unwritten rule, motions from the opposition are regularly rejected by the majority and vice versa. On the other hand, we find evidence that intra-party deliberation plays an important role in the construction of positions of the respective party group. Here, conflicts that are based on 
different policy perspectives are tackled not only through bargaining but also by arguing (cf. Schöne 2010, 150-151).

However, as expected, the intensity of the process of intra-party deliberation further limits openness to changing party positions in inter-party deliberation, because of an implicit rule that potential modifications would have to be discussed and confirmed in the party group again. Committee members are drawn into a conflict between legitimate roles: as policy experts, they might be open to the arguments from their colleagues from other parties, but as representatives of their own party they have to execute the positional decisions of their groups, which in turn are regularly based on deliberative processes. ${ }^{7}$

Although committee members do not expect committee or plenary deliberation to change their or their opponent's positions within in process, they still feel compelled by the formal and informal deliberative rules that constitute the discursive logic of the setting to justify their own positions and their rejection of others'. Moreover, they see a clear difference between (normally non-public) committee deliberation and public floor debate: while the first one still mainly addresses the participants of the internal decision-making process, the latter is in the first instance directed to the broader public. At the same time, they value floor debates highly, not only because they allow them to justify their own point of view to an outside audience but also because they see the chance to influence future agenda-setting and position-building processes by contesting competing political positions (Schäfer 2017, 233-243).

These results suggest a functional differentiation of deliberation within the German federal parliament: Whereas in intra-party arenas deliberation contributes to the building of common positions (the integrative function), in inter-party arenas deliberation has primarily the function of justifying own and of contesting opponent's positions. While the parliamentary context leaves some room for less ideologically polarized issues to be informally and cooperatively discussed among members of different party groups, in the formal arenas and especially in plenary debates the contestation function clearly dominates. This, however, can contribute to position building within parties and the broader public in the long run.

\subsection{Comparing deliberative profiles of parliaments}

Since parliamentary deliberation is a central element of the larger political process in society, the next question is whether we can also identify characteristic deliberative profiles of 
parliaments that are associated with a tendency towards either integration or contestation for the respective political system. In order to illustrate what the contextualised model implies for such a comparison of parliaments, this section looks at three different cases that vary in their conditions for the positional logic: the German Bundestag with its clear-cut majorities and a high degree of factional cohesion; the US House of Representatives with its less clear majorities and rather low party group cohesion (Owens 2003, 18); and the European Parliament with its flexible, shifting majorities of diverse coalitions and a neither strong nor really weak cohesion of the party groups due to its transnational character and its lack of effective links to the executive (Hix and Høyland 2013). The positional logic is likely to be strongest in the German case, weakest in the American case, the European Parliament lying in between.

Regarding the discursive logic, we can for the sake of analytical simplification assume roughly equal initial conditions due to similar parliamentary procedures in the three cases. If one brackets off the fact of issue structuration for the moment and directly compares the hypothetical performance of the three parliaments in fulfilling deliberative functions, one would expect to find the contestation function (anchored in a confrontational mode of deliberation) to be strongest in the Bundestag and weakest in the House of Representatives. By contrast, one might predict the House to be strongest and the Bundestag weakest with regard to integrative functions (anchored in integrative modes of deliberation), with the European Parliament falling between the two extremes.

This positioning of the cases is relevant for the relation of bargaining and arguing as well. The House of Representatives is the most promising candidate for bargaining as an alternative to arguing because bargaining requires that negotiation partners have veto power and the ability to offer something to each other. This is not the case when we have clear-cut majorities and high party group cohesion, such as in the Bundestag. Here, the majority normally does not need the consent of the minority and the opposition has few opportunities to trade on influence. This leaves arguing as the primary mode for addressing disagreement. In the American case, where majorities are less clear and party group cohesion less stable, bargaining can be an attractive alternative to arguing in order to tackle conflicts both within and between party groups. Individual members of Congress can offer to shift their support to strengthen or weaken the veto power of their party groups. The European Parliament generally provides better conditions for bargaining than the German case but also somewhat 
worse conditions than the American case. This is because shifting majorities and only moderately strong party group coherence blur the lines between supporters and opponents of positions. This makes it hard to stipulate veto positions and, in turn, makes bargaining less attractive than in the American case. This suggests that high party group cohesion and clear majorities foster confrontational forms of deliberation, whereas low party group cohesion and less clear majorities promote cooperative forms of deliberation and bargaining.

This hypothetical analysis demonstrates how we can construct deliberative profiles for diverse types of parliaments. This is not to suggest that deliberative profiles are monolithic. Of course, internal variation will occur as issue structures change and the polarization potential evolves through the parliamentary process itself. Moreover, parliaments can fulfil diverse deliberative functions by addressing diverse issues differently. However, these hypotheses do reflect overall tendencies or trends in the functional performance of specific parliaments that could be tested empirically.

How we value or assess the tendencies of our cases must depend on the character of the larger political system in which the respective parliament is embedded. The question, then, is what parliamentary deliberation can achieve for the other parts of the democratic system. In the German case, a politicising tendency of parliamentary deliberation might counterbalance the consensual political culture of the country by bringing issues and arguments onto the political agenda that would otherwise be silenced. The American case might systematically profit from conciliatory forms of deliberation and negotiation in the House of Representatives, ameliorating confrontational deadlocks in the political process that arise from the constitutional division of powers between executive and legislative branches. Considering the mixed profile of the European case, an integrational tendency in parliamentary deliberation could help integrate a political system that encompasses diverse political cultures. A potential downside of this consensual functioning of parliamentary deliberation, and one identified for the European Union (e.g. Pérez 2013), is that it may be less conducive to the development of a political public sphere where the political status quo can be contested. Thus, one could argue that the European Parliament sometimes needs more partisan, confrontational modes of deliberation that clearly indicate competing political alternatives.

Thus, while research within the framework of the ethical-evaluative paradigm, exemplified by Landwehr and Holzinger (2010) and Steiner et al. (2004), produces a rather sceptical 
diagnosis of deliberative performance of parliaments that identify rather low degrees of discourse quality, the contextualised-systemic approach would provide a more balanced base for the evaluation of deliberative performance within the political system. The approach not only captures the more conciliatory forms and integrative functions, but also the more confrontational modes and contestation functions of parliamentary deliberation. In addition, it provides the analytical tools to explain the relationship between specific institutional configurations, issue structures, and the forms and functions of deliberation across the diverse arenas of parliament.

\section{Conclusion}

This article has addressed the complicated relationship between deliberation and representation by analytically reconstructing the institutional logics embedded in parliaments, the major representative institution of liberal democracies. The article takes a critical stance towards prevailing approaches to the study of parliamentary deliberation. In contrast to the ethical-evaluative paradigm that applies generalised theoretical measures to predominantly individual-level behaviour and focuses on consensual effects, it has introduced a contextualised-systemic approach that accounts for different conditions, forms and functions of parliamentary deliberation.

According to this approach, the parliamentary context of deliberation is undergirded by a tension between two democratically legitimated institutional logics. The balance between positional and discursive logics and the issue structure of a conflict shape the deliberative orientation of the actors, the form of deliberation they adopt, and the subsequent deliberative functions. Although a pure positional logic would prevent deliberation from having any effect, both logics are important for understanding how deliberation fulfils different democratic functions. However, only a combination of those functions can plausibly provide legitimacy to collective decisions. Whereas minorities must have recourse to the legitimate option of contesting decisions and the possibility of winning the majority in the future, majorities can expect the conflict to be legitimately settled for the time being.

The framework was applied to a comparative analysis of parliaments in order to demonstrate its analytic potential at a reasonably abstract level, with hypotheses derived for a more detailed empirical work. The case of the German Bundestag shows how deliberation follows a 
functional differentiation in the parliamentary process according to the needs of diverse arenas. The comparison of the German case with the US House of Representatives and the European Parliament indicates how the framework can be applied to reconstruct deliberative profiles of parliaments, and how their deliberative performance can be evaluated in relation to the democratic requirements of the surrounding political systems.

Three conclusions can be drawn for future research. First, the approach outlined here suggests that empirical deliberation research should take into account more radically the contexts in which deliberative practices are embedded, in order to understand their dynamics and democratising potential in different contexts. Second, while deliberative democratic theory has broadened its focus to the value of non-deliberative forms of communication for the deliberative system, it still has to acknowledge and analytically consider the diversity of modes of deliberation that promote different valuable democratic functions. Moreover, the contextual-systemic approach helps to re-think questions of institutional design for promoting specific democratic purposes. Third, although the analysis focuses on parliamentary deliberation, insights can be relevant for other representative contexts as well. The contextualised-systemic framework provides the conceptual and analytical tools for reconstructing the specific interdependence of deliberation and representation not only in diverse types of parliaments but also in settings such as mini-publics, parties, NGOs and other forums, as long as they both use deliberative practices and make representative claims.

\section{Notes}

\footnotetext{
${ }^{1}$ For an overview of the state of the art, see Bächtiger (2014) and Quirk and Bendix (2011). For an early exception, see Uhr (1998).

${ }^{2}$ The DQI inspired a range of consecutive studies that focus on certain aspects of parliamentary deliberation, such as the relationships between institutional and cultural factors influencing discourse quality (Bächtiger and Hangartner 2010), apply the measurement to other parliaments (Lord and Tamvaki 2013; Roger and Schaal 2013), or apply it to other settings (Gerber et al. 2014).

${ }^{3}$ Similar claims are made by Thomson $(2008,504)$ and Warren (2007).

${ }^{4}$ I borrow this term from neo-institutionalist organisation theory (Friedland and Alford 1991), where it is used to describe social structures on the macro-level of societies. I apply the term to phenomena on the organisational level of the political institutions of the parliament.

${ }^{5}$ Even if we adopt a constructivist conception of representation and acknowledge that responsiveness is not always linked to a pre-established position within a constituency but rather yet to be constructed in relation to potential future positions (Disch 2011), this process will create representative claims that bind the claimant to the expectations of the audience if it shall be accepted.
} 


\footnotetext{
${ }^{6}$ Set out in some detail in Schäfer $(2017,127-259)$.

7 The representational relationships to the respective electoral constituency can further complicate role performance. Generally speaking, representing the regional constituency can support either the discursive or the positional logic within the parliamentary process depending on whether constituency interests or perspectives are in line or in conflict with party positions (Schäfer 2017, 265).
}

\section{Acknowledgements}

The author would like to thank three anonymous reviewers as well as John Parkinson and the other co-editors of the Australian Journal of Political Science for their helpful comments and suggestions. I also thank Raphaël Kies, Donald Bello Hutt and the other participants at the ECPR Joint Session on Deliberative Systems in Comparative Perspective at Pisa, Italy, in April 2016 for their insightful feedback on an earlier draft of this article.

\section{Disclosure statement}

No potential conflict of interest was reported by the author

\section{References}

Bächtiger, André. 2014. "Debate and deliberation in legislatures." In The Oxford handbook of legislative studies, edited by Shane Martin, Thomas Saalfeld, and Kaare W. Strøm, 145166. New York: Oxford University Press.

Bächtiger, André, and Dominik Hangartner. 2010. "When deliberative theory meets empirical political science. Theoretical and methodological challenges in political deliberation." Political Studies 58: 609-629.

Bächtiger, André, Simon Niemeyer, Michael Neblo, Marco R. Steenbergen, and Jürg Steiner. 2010. "Disentangling diversity in deliberative democracy. Competing theories, their blind spots and complementarities." Journal of Political Philosophy 18: 32-63.

Bohman, James. 2012. "Representation in the deliberative system." In Deliberative systems. Deliberative democracy at the large scale, edited by John R. Parkinson and Jane J. Mansbridge, 72-94. Cambridge: Cambridge University Press.

Chambers, Simone. 2003. "Deliberative democratic theory." Annual Review of Political Science 6: 307-326.

Deutscher Bundestag. 2010. Plenarprotokoll 17/68. Berlin: Parlamentsdokumentation. URL: http://dip21.bundestag.de/dip21/btp/17/17068.pdf. Consulted 6 May 2017

Disch, Lisa. 2011. "Toward a Mobilization Conception of Democratic Representation." American Political Science Review 105: 100-114. 
Dryzek, John S., and Simon Niemeyer. 2008. "Discursive representation." American Political Science Review 102: 481-493.

Dryzek, John S. 2000. Deliberative democracy and beyond. Liberals, critics, contestations. Oxford: Oxford University Press.

Elster, Jon. 1999. "Arguing and bargaining in two constituent assemblies." University of Pennsylvania Journal of Constitutional Law 2: 345-421.

Friedland, Roger, and Robert R. Alford. 1991. "Bringing Society Back In: Symbols, Practices, and Institutional Contradictions." In The New institutionalism in organizational analysis, edited by Walter W. Powell and Paul DiMaggio, 232-263. Chicago: University of Chicago Press.

Gerber, Marlène, André Bächtiger, Irena Fiket, Marco Steenbergen, and Jürg Steiner. 2014. "Deliberative and non-deliberative persuasion. Mechanisms of opinion formation in EuroPolis.” European Union Politics 15: 410-429.

Goertz, Gary, and James Mahoney. 2012. A tale of two cultures. Qualitative and quantitative research in the social sciences. Princeton: Princeton University Press.

Habermas, Jürgen. 1987. Theorie des kommunikativen Handelns. Band 1 Handlungsrationalität und gesellschaftliche Rationalisierung. Frankfurt am Main: Suhrkamp.

Habermas, Jürgen. 1996. Between facts and norms. Contributions to a discourse theory of law and democracy. Translated by William Rehg. Cambridge: MIT Press.

Habermas, Jürgen. 2005. "Concluding comments on empirical approaches to deliberative politics." Acta Politica 40: 384-392.

Habermas, Jürgen. 2007. „Kommunikative Rationalität und grenzüberschreitende Politik: eine Replik.“ In Anarchie der kommunikativen Freiheit. Jürgen Habermas und die Theorie der internationalen Politik, edited by Peter Niesen and Benjamin Herborth, 406-459. Frankfurt am Main: Suhrkamp.

Hix, Simon, and Bjørn Høyland. 2013. "Empowerment of the European Parliament." Annual Review of Political Science 16: 171-189.

Holzinger, Katharina. 2005. "Context or conflict types: which determines the selection of communication mode." Acta Politica 40: 239-254.

Kuyper, Jonathan W. 2016. "Systemic Representation. Democracy, Deliberation, And Nonelectoral Representatives.” American Political Science Review 110: 308-324.

Landwehr, Claudia, and Katharina Holzinger. 2010. "Institutional determinants of deliberative interaction.” European Political Science Review 2: 373-400.

Lijphart, Arend. 1992. "Introduction." In Parliamentary versus presidential government, edited by Arend Lijphart, 1-27. Oxford, New York: Oxford University Press.

Lord, Christopher, and Dionysia Tamvaki. 2013. "The politics of justification? Applying the 'Discourse Quality Index' to the study of the European Parliament." European Political Science Review 5: 27-54.

Mansbridge, Jane J., James Bohman, Simone Chambers, Thomas Christiano, Archon Fung, John R. Parkinson, Dennis F. Thompson, and Mark Warren. 2012. "A systemic approach to deliberative democracy." In Deliberative systems. Deliberative democracy at the large 
scale, edited by John R. Parkinson and Jane J. Mansbridge, 1-26. Cambridge: Cambridge University Press.

March, James G., and Johan P. Olsen. 1996. "Institutional perspectives on political institutions." Governance 9(3): 247-264.

Mouffe, Chantal. 2005. On the political. London: Routledge.

Owens, John E. 2003. "Explaining Party Cohesion and Discipline in Democratic Legislatures: Purposiveness and Contexts." The Journal of Legislative Studies 9(4): 12-40.

Parkinson, John R. 2006. Deliberating in the real world. Oxford: Oxford University Press.

Pérez, Francisco S. 2013. Political communication in Europe. The cultural and structural limits of the European public sphere. New York: Palgrave Macmillan.

Pitkin, Hanna F. 1967. The concept of representation. Berkeley: University of California Press.

Plotke, David. 1997. "Representation is Democracy." Constellations 4(1): 19-34.

Quirk, Paul J., and William Bendix. 2011. "Deliberation in Congress." In The Oxford handbook of the American Congress, edited by Eric Schickler and Frances E. Lee, 550575. New York: Oxford University Press.

Roger, Léa, and Gary S. Schaal. 2014. "The quality of deliberation in two committees of the European Parliament. The neglected influence of the situational context and the policymaking stage." Politics and Governance 1(2): 151-169.

Rüb, Friedbert W. 2009. "Über das Organisieren der Regierungsorganisation und über Regierungsstile. Eine praxeologische Perspektive." Österreichische Zeitschrift für Politikwissenschaft 38(1): 43-60.

Sanders, Lynn M. 1997. “Against deliberation.” Political Theory 25(3): 347-376.

Saretzki, Thomas. 2009. "From bargaining to arguing, from strategic to communicative action? Theoretical distinctions and methodological problems in empirical studies of deliberative policy processes." Critical Policy Studies 3(2): 153-183.

Saward, Michael. 2010. The representative claim. Oxford: Oxford University Press.

Schäfer, Andreas. 2017. Zwischen Repräsentation und Diskurs. Zur Rolle von Deliberation im parlamentarischen Entscheidungsprozess. Wiesbaden: Springer VS.

Schöne, Helmar. 2010. Alltag im Parlament. Parlamentskultur in Theorie und Empirie. Baden-Baden: Nomos.

Sieberer, Ulrich. 2006. "Party unity in parliamentary democracies: A comparative analysis." The Journal of Legislative Studies 12(2): 150-178.

Steiner, Jürg, André Bächtiger, Markus Spörndli, and Marco R. Steenbergen. 2004. Deliberative politics in action. Analyzing parliamentary discourse. Cambridge: Cambridge University Press.

Thompson, Dennis F. 2008. "Deliberative democratic theory and empirical political science." Annual Review of Political Science 11(1): 497-520.

Uhr, John. 1998. Deliberative democracy in Australia. The changing place of Parliament. Cambridge: Cambridge University Press. 
Urbinati, Nadia. 2000. "Representation as Advocacy. A Study of Democratic Deliberation." Political Theory 28(6): 758-786.

Urbinati, Nadia, and Mark E. Warren. 2008. "The Concept of Representation in Contemporary Democratic Theory." Annual Review of Political Science 11 (1): 387-412.

Warren, Mark E. 2007. "Institutionalizing Deliberative Democracy." In Deliberation, participation and democracy. Can the people govern?, edited by Shawn W. Rosenberg, 272-288. Basingstoke: Palgrave Macmillan.

Warren, Mark E., Jane J. Mansbridge, André Bächtiger, Maxwell A. Cameron, Simone Chambers, John Ferejohn, Alan Jacobs, et al. 2016. "Deliberative Negotiation." In Political Negotiation: A Handbook, edited by Jane J. Mansbridge and Cathie J. Martin, 141-196. Washington, DC: Brookings Institution Press.

White, Stephen K., and Evan R. Farr. 2012. “No-Saying' in Habermas.” Political Theory 40 (1): $32-57$.

White, Jonathan and Lea Ypi. 2011. "On Partisan Political Justification.” American Political Science Review 105 (02):381-396.

Young, Iris M. 2000. Inclusion and democracy. Oxford: Oxford University Press. 